GLOBAL WATER PATHOGEN PROJECT

PART THREE. SPECIFIC EXCRETED PATHOGENS: ENVIRONMENTAL AND EPIDEMIOLOGY ASPECTS

\title{
TOXOCARA SPP.
}

\section{Rosemary McManus}

Independent Consultant

Dublin, Ireland

Clare Hamilton

Moredun Research Institute

Penicuik, United Kingdom

Celia Holland

Trinity College Dublin

Dublin, Ireland 


\section{Copyright:}

\section{cc) (i) (2) \\ BY SA}

This publication is available in Open Access under the Attribution-ShareAlike 3.0 IGO (CC-BY-SA 3.0 IGO) license (http://creativecommons.org/licenses/by-sa/3.0/igo). By using the content of this publication, the users accept to be bound by the terms of use of the UNESCO Open Access Repository (http://www.unesco.org/openaccess/terms-use-ccbysa-en).

\section{Disclaimer:}

The designations employed and the presentation of material throughout this publication do not imply the expression of any opinion whatsoever on the part of UNESCO concerning the legal status of any country, territory, city or area or of its authorities, or concerning the delimitation of its frontiers or boundaries. The ideas and opinions expressed in this publication are those of the authors; they are not necessarily those of UNESCO and do not commit the Organization.

\section{Citation:}

McManus, R., Hamilton, C.M. and Holland, C.V. (2018). Toxocara spp. In: J.B. Rose and B. Jiménez-

Cisneros (eds), Water and Sanitation for the 21st Century: Health and Microbiological Aspects of Excreta and Wastewater Management (Global Water Pathogen Project). (L. Robertson (eds), Part 3: Specific Excreted Pathogens: Environmental and Epidemiology Aspects - Section 4: Helminths), Michigan State University, E. Lansing, MI, UNESCO. https://doi.org/10.14321/waterpathogens.42

Acknowledgements: K.R.L. Young, Project Design editor; Website Design: Agroknow (http://www.agroknow.com)

Last published: April 27, 2018 


\section{Summary}

Toxocara is a genus of nematodes that are cosmopolitan gastrointestinal species of both companion and feral animals that act as definitive hosts. Toxocara canis infects both domestic dogs and foxes, whereas the hosts of $T$. cati include the domestic cat and other felids. Widespread environmental contamination, as a consequence of eggs being shed in the host faeces, facilitates infection of abnormal or paratenic hosts, that include mice, domestic animals, and humans. In such hosts, larvae undergo a somatic migration through the tissues and organs of the body but fail to develop to maturity as adult worms in the intestine. The presence of migrating larvae in the tissues contributes to pathology that is dependent upon the intensity of infection and the location of the larvae and is associated with the human disease known as toxocariasis. Although our understanding of the public health significance of toxocariasis in humans is incomplete, seroprevalence studies provide evidence for high levels of exposure in the human population. Toxocariasis is now considered to be the most common human parasitic infection in the Unites States, particularly among the impoverished. Furthermore, the infection is also common in developing countries and its global importance is likely to be significantly underestimated.

Humans exhibit a number of clinical entities including visceral larva migrans, ocular toxocariasis, and cerebral toxocariasis. Larval involvement in the eye, with consequent visual impairment, remains the most devastating sequela. However, recent evidence from a large-scale sample of American children of an association between seropositivity and cognitive defects may prove to be of even broader public health significance.

One particular lacuna in our knowledge of the epidemiology of toxocariasis is the relative importance of different modes of transmission. Humans become exposed to infection by ingestion of embryonated eggs, either due to handling or consuming contaminated soil or food, or eating meat products containing third-stage larvae.

The literature on environmental contamination with Toxocara spp. ova is almost entirely confined to examination of soil. The presence of potentially infective or infective eggs of Toxocara spp. in the environment is one of the key routes of transmission to humans. Infected definitive hosts such as dogs, cats and to a lesser extent foxes release their faeces, and the helminth eggs within them, into the environment. However, our understanding of the relative importance of the different host sources is incomplete. In contrast to soil, few studies have described the recovery of Toxocara eggs from water. In one study from Australia, the highest prevalence of helminth eggs detected in liquid sludge from urban wastewater treatment plants was Toxocara. A recent review of methods for the quantification of soil-transmitted helminthes in environmental samples, highlighted four key methodological issues - environmental sampling, recovery from environmental matrices, quantification, and viability assessment. This chapter will highlight the existing data on environmental contamination with Toxocara ova and the significant gaps in our knowledge with respect to the presence of Toxocara ova in water.

\subsection{Epidemiology of the Disease and Pathogen}

\subsection{Global Burden of Disease}

The zoonotic roundworms Toxocara canis and T. cati are not only present worldwide in their definitive hosts (canids and felids) where by dogs and cats (and related species) excrete the ova in their faeces; they also frequently occur in other paratenic, or accidental hosts, including humans. In those so-called paratenic hosts, the larvae do not develop into the adult stage, but rather migrate throughout the somatic tissue and persist as infectious L3 stage for extensive periods (Strube et al., 2013). Thus human faeces and sewage are not involved in the disease transmission.

Toxocariasis is considered to be one of the most widespread public health and economically important zoonoses that humans can contract (Macpherson, 2013). Recent research indicates that toxocariasis is the most common human parasitic worm infection in the United States, affecting millions of Americans living in poverty (Hotez and Wilkins, 2009). However, our current understanding of the global impact and economic cost of human toxocariasis is poor because there is insufficient clinical awareness and no clear repository for the efficacy of clinical, laboratory and treatment interventions (Smith et al., 2009).

\subsubsection{Global distribution}

Toxocara spp. have a worldwide distribution and are particularly prevalent in the tropics and sub-tropics, in less industrialised nations where dog treatment and population control is limited (Macpherson, 2013). Infection is also highly prevalent in many developing countries and its global importance may be greatly underestimated (Hotez and Wilkins, 2009). Worldwide seroepidemiological surveys show human toxocariasis to be among the most frequently occurring helminthiases (Fan et al., 2015a). In a study carried out in the United States, Won et al., (2008) found that seroprevalence was $13.9 \%$ and was higher in nonHispanic blacks (21.2\%) than non-Hispanic whites (12\%) or Mexican Americans (10.7\%). In developed countries, such as the United States, Japan, Canada, Germany, United Kingdom, Italy, France, and Russia, seroprevalence has been found to be highest in rural areas, ranging from 35\% to $42 \%$, falling to $15 \%$ to $20 \%$ in semirural zones and to $2 \%$ to $5 \%$ in urban areas (Fillaux and Magnaval, 2013; Magnaval et al., 2001). Higher seroprevalences have been reported from developing countries like Nigeria (30\%), Brazil (36\%), Swaziland (44.6\%), Malaysia (58\%) Indonesia (63.2\%), Nepal (81\%), Marshall Islands (86.8\%), and La Reunion (93\%) (Smith \& Noordin, 2006; Liao et al., 2010; Rubinsky-Elefant et al., 2010; Fu et al., 2014). However, as previously mentioned, an accurate analysis of seroprevalences between different countries and studies is hindered by the different methodologies used to detect 
infections (Western Blot or ELISA), different cutoff titers, and the difficulties in linking infection, titers, and symptomatic disease (Smith et al., 2009; Alderete et al., 2003).

\subsubsection{Symptomatology}

At present there are four distinct clinical entities associated with human toxocariasis - these are visceral larva migrans (VLM), ocular larva migrans (OT), covert toxocariasis (CT) and cerebral toxocariasis or neurotoxocariasis (NT) (Fan et al., 2015b). However, the relationship between specific symptoms and signs of these clinical entities is not always clear cut or well understood due to the non specific nature of most of the symptoms (Smith et al., 2009).

\subsubsection{Visceral larva migrans (VLM)}

VLM was first described by Beaver and colleagues in 1952 when the presence of Toxocara larvae was detected in eosinophilic granulomata in liver biopsies taken from three children who underwent laparotomy. VLM therefore refers to the migration of Toxocara larvae through the somatic tissues and the consequent pathogenesis. The disease is characterized by persistent and eosinophilia, hepatomegaly, respiratory symptoms and anaemia. However, the role of Toxocara in asthma remains unclear with contradictory results. For example, asthma and recurrent bronchitis was significantly associated with Toxocara seropositivity in young Dutch children of elementary school age (Buijs et al., 1997) but such an association was not detected in children aged between 2 and 15 years of age in the USA (Sharghi et al., 2001). However, more recently Walsh, (2011) showed a significant association between diminished lung function and previous infection with Toxocara spp. in adults aged between 17 and 65 years old in the USA.

Cutaneous manifestations of toxocariasis have been reported including rash, urticaria and hypodermic nodules (Ehrhard and Kernbaum, 1979), however case reports predominate and a systematic population-based approach is lacking (Smith et al., 2009). A 2008 review conducted by Gavignet et al. (2008) concluded that the most commonly encountered skin manifestations associated with toxocariasis are chronic pruritus or prurigo, different forms of eczema, and chronic urticaria.

\subsubsection{Ocular toxocariasis (OT)}

In 1950, Wilder discovered granulomata containing nematode larvae within the eyes of children that had been enucleated due to suspected retinoblastoma. Subsequently, what are now known to be third-stage larvae of Toxocara, were described by Nichols, (1956) within the observed granulomata. These observations led to the description of ocular toxocariasis (OT).

OT is described as a relatively rare disease primarily observed in children (Taylor, 2006). OT is generally characterized by unilateral vision impairment, strabismus and leukocoria, although the clinical presentation may vary depending upon the site of larval involvement and the immune response of the host (Dinning et al., 1988). Blindness in one or both eyes is rarely observed (Taylor, 2001). However, a recent web-based survey conducted by the Centers for Disease Control (CDC, 2011) reported the most common symptom among those surveyed (68 patients diagnosed with OT) was vision loss (83\%) with $68 \%$ of patients exhibiting permanent vision loss. Population-based estimates of the prevalence for OT are lacking (holl). A study of 121,156 schoolchildren carried out in Ireland (Good et al., 2004) recorded a prevalence of 6.6 cases per 100,000 persons (increasing to 9.7 cases per 100,000 persons when both definite and strongly suspected cases were included).

\subsubsection{Covert toxocariasis (CT)}

Covert toxocariasis has been shown to be a cause of recurrent abdominal pain in childhood and is considered more common than other clinical forms of toxocariasis (Nathwani et al., 1992). It describes patients in whom positive Toxocara serology is associated with a number of systemic and localised symptoms and signs (notably abdominal pain), but not VLM or OT. CT was initially described by Bass et al., $(1983,1987)$ in the USA and Taylor et al., (1987) in Ireland. Glickman et al., (1987) also describe a similar syndrome in France, but named it 'common toxocariasis'.

Covert toxocariasis was characterised by a moderate Toxocara elisa titre of $>1: 50$, a normal or mildly elevated blood eosinophil count and multiple minor symptoms (such as abdominal pain, headache and/or cough) (Bass et al., 1983, 1987; Taylor et al., 1987). In addition, Glickman et al., (1987) described weakness, pruritis, rash, difficulty in breathing and abdominal pain as the main symptoms. A quarter of patients have no eosinophilia and although symptoms regress after treatment, they may persist for months or years (Nathwani et al., 1992).

\subsubsection{Cerebral toxocariasis or neurotoxocariasis (NT)}

Cerebral or neurotoxocariasis occurs in a paratenic host when the aberrant migration of larvae results in the organisms arresting in the brain or spinal cord. NT in humans was first described by Beautyman and Woolf in 1951 when an autopsy study of a child who died of poliomyelitis was carried out, in whom an Ascaris larva was found in the left thalamus. In 1997, Magnaval et al. conducted a case-control study finding that T. canis larval invasion of the brain rarely induces recognizable neurological signs, possible due to repeated low dose infection. In the last 30 years, however, an increasing number of clinical NT cases due to larval invasion of the brain or spinal cord have been recorded due to improved methods of diagnosis. Many clinical symptoms have been described and include cerebral vasculitis, myelitis, eosinophilic meningoencephalitis, meningitis, encephalitis, seizures and cognitive deficits (Holland and Hamilton, 2013; Caldera et al., 2013; Finsterer and Auer, 2007). The number of cases of NT will tend to be underestimated due to nonspecific clinical signs when compared with VLM, as well as due to a lack of availability of appropriate testing, 
thus leading to possible underdiagnosis (Holland and Hamilton, 2013; Hotez and Wilkins, 2009).

\subsection{Taxonomic Classification of the Agent}

Recently, MacPherson (2013) described at least 14 species of ascarid with zoonotic potential ranging from the ubiquitious T. canis (Holland and Smith, 2006) to the cryptic T. pteropodis (Prociv, 1989) and the emerging and highly pathogenic Baylisascaris spp (Graeff-Teixeira et al., 2016). However, despite zoonotic potential, the importance of many of these species to human health is likely to be negligible. What is quite clear is the central importance of $T$. canis due to the widespread distribution of the domestic dog. However, because it is not possible to distinguish Toxocara species serologically (Poulsen et al., 2015), we still do not know the relative importance of $T$. cati to human toxocariasis (Fisher, 2003). The nematode Toxascaris leonina is also a zoonotic ascarid parasite of the dog and cat (Miyazaki, 1991). However, the role of $T$. leonina in human disease remains unknown particularly given our current inability to distinguish Toxocara spp. serologically (Holland, 2017).

\subsubsection{Taxonomy}

Toxocara spp. are parasitic nematodes belonging to the Phylum Nematoda, Order Ascaridia, Superfamily Ascaridoidea, Family Ascarididae, Subfamily Toxocarinae and Genus Toxocara. The more prevalent species within the genus are $T$. canis, $T$. cati and $T$. vitulorum. Among a total of 21 species within the Toxocara genus, two are of significant public health concern, namely, $T$. canis and $T$. cati, for which dogs and cats, respectively, are the definitive hosts (Fan et al., 2015b).

\subsubsection{Physical description of the agent}

With regards to T. canis and T. cati, the eggs appear pitted on the surface. T. canis eggs measure $75-90 \mu \mathrm{m}$ in diameter and are spherical whereas $T$. cati eggs measure $65-70 \mu \mathrm{m}$ in diameter and have an oblong shape. The third stage $T$. canis larvae that hatch from the eggs (Brunaska et al., 1995) have an average length of 404 microns and an average width of 18 - 20 microns (Nichols, 1956). T. cati larvae that hatch from eggs have similar average lengths but are slightly thinner with an average width of 16 - 17 microns (Nichols, 1956). Adults have complete digestive systems and three lips with dentigerous ridges and occur in the intestine of the definitive host. O'Lorcain, (1994a) found that male worms had a mean length of $70 \mathrm{~mm}$ and $48 \mathrm{~mm}$ for $T$. canis and T. cati respectively. In the same study, egg-bearing females were found to have a mean length of $127 \mathrm{~mm}$ (T. canis) and $68 \mathrm{~mm}$ (T. cati). Immature (non-egg-bearing) females had a mean length of $58 \mathrm{~mm}$ and $40 \mathrm{~mm}$ for $T$. canis and $T$. cati respectively.

\subsubsection{Tissue Tropism/Cellular receptors/Latency}

In the definitive host (eg., the dogs and cats), eggs are ingested, hatch in the small intestine and larvae penetrate the gut wall and enter the circulatory system. They reach the liver about 24 hours post infection via portal circulation through venous capillaries (Webster, 1958). About twelve hours later, larvae continue migration to the heart where the lung is reached via the pulmonary artery (Strube et al., 2013). From here, larvae may penetrate the alveoli wall leading to migration to the pharynx through bronchioles and trachea (Strube et al., 2013). After coughing and swallowing, larvae begin to develop into adult worms in the intestine, which occurs about 7-15 days post tracheal migration (Sprent, 1958). Eggs are then excreted in faeces into the environment and undergo embryonation which may take as little as three weeks or up to several months depending on the environmental and climatic conditions.

In the human paratenic host, the infective embryonated ova are ingested and hatch 2-4 hours later (Strube et al., 2013). Commonly, larvae hatch after consumption, penetrate the intestinal wall and during the so-called hepato-pulmonary phase migrate via the circulatory system to the liver and then to the lungs. From there, they continue migration into the systemic circulation (Strube et al., 2013), and can travel through tissue and the circulatory systems to the eye (OT), the liver/lung (VLM/CT) or the brain/spinal cord (NT). Here they enter an arrested stage of development. Migration routes as well as predilection sites depend on the host species, however nearly all organs may be affected with varying degrees of larval burdens.

\subsection{Transmission}

Adult worms of Toxocara spp. are found in the intestine of a wide range of domestic and feral definitive hosts. $T$. canis infects domestic dogs (O'Lorcain, 1994a), foxes (Roddie et al., 2008), wolves (Segovia et al., 2001) and coyotes (Wapenaar et al., 2013) whereas T. cati infects domestic and wild felids (Fisher, 2003). In contrast $T$. leonina infects both dogs and cats (Miyazaki, 1991). T. malaysiensis has been described as an ascarid of cats in Malaysia and China (Zhu et al., 1998; Gibbons et al., 2001; Li et al., 2006) and more recently from Vietnam (Le et al., 2016).

Both dogs and cats can become infected by ingesting infective eggs. In dogs, hatched larvae enter the bloodstream and travel via the liver to the lungs (Overgaauw, 1997). Larvae can then migrate up the trachea, where they are swallowed and then return to the small intestine to develop into adult worms. Where somatic migration occurs, larvae do not develop into adult worms but can remain in an arrested state within the tissues for long periods of time. This arrested state may change if the dog is a female and becomes pregnant; larvae can reactivate and migrate across the placenta thereby infecting the offspring in utero or alternatively larvae migrate to the mammary glands of the bitch and infect puppies during lactation (Overgaauw, 1997). However, lactational transmission is much less common than prenatal transmission (Burke and Roberson, 1985) but increases if the bitch is infected during mid-pregnancy or lactation (Burke and Roberson, 1985). In contrast, in cats transmammary transmission of $T$. cati does occur if cats are infected during lactation but there is no evidence of 
transplacental transmission (Coati et al., 2004). Tracheal migration and the consequent development of patent infections in the intestine are more common in young dogs but multiple studies have demonstrated that adult dogs infected with low doses of infective eggs can also develop patent infections in the intestine emphasising their importance as reservoirs of infection (Dubey, 1978; Maizels and Meghji, 1984; Fahrion et al., 2008).

It has been suggested that the ingestion of third-stage larvae via predation may be a more important route of transmission for cats. Until recently, no data existed on the species identity of the larvae found in feral paratenic hosts. This was considered a significant gap in our knowledge (Holland, 2017). However, recently Krüchen et al., (2017) sampled 257 small rodents from Berlin, Germany and detected T. canis, T. cati and Parascaris DNA in the brains or skeletal muscle of $3.1 \%, 1.6 \%$ and $0.4 \%$ animals respectively. In contrast, serology by means of ELISA revealed a prevalence of $14.2 \%$ for $T$. canis.

More recently, it has been suggested that direct contact with contaminated dog or cat hair maybe another potentially important source of infection to humans (Wolfe and Wright, 2003; Roddie et al., 2008; Overgaauw et al., 2009). However, recent epidemiological evidence from a range of geographical locations and differing dog populations suggests that contact with well-cared-for dogs poses a low risk of infection (Keegan and Holland, 2010; evidence reviewed in Holland, 2017).

Fecund adult worms shed eggs in their faeces that can then contaminate the environment and under appropriate conditions of temperature and moisture, embryonate and hence become potentially infective (Traversa et al., 2014). Humans may become infected with Toxocara spp. through the ingestion of eggs directly from soil or indirectly via contaminated hands, food items for example unwashed, contaminated fruit and vegetables (Klapéc and Borecka, 2012) or utensils (Glickman and Schantz, 1981).

Toxocara eggs can infect a wide range of paratenic hosts including small mammals, birds, earthworms and humans (Holland and Hamilton, 2006). Toxocara larvae do not develop to adulthood in such hosts but remain as thirdstage larvae in their tissues (Brunaska et al., 1995; Strube et al., 2013). Paratenic hosts can act as food items for both definitive hosts (dogs and cats) and humans. Transmission via the consumption of raw or undercooked meat including chicken and liver has been implicated in human infection (Nagakura et al., 1989; Yoshikawa et al., 2008; Noh et al., 2012).

Therefore, in summary there are four key epidemiological reservoirs of Toxocara (Overgaauw and Van Knapen, 2013) - the presence of adult worms in the intestine of domestic and feral definitive hosts (dogs, cats and foxes), the presence of eggs in the environment, the presence of larvae in the tissues of paratenic hosts and somatic larvae in the tissues of definitive hosts (particularly in dogs - see Coati et al., 2004). With respect to the focus of this chapter, it is clear that the presence of adult worms in the intestine of feral and domestic definitive hosts and their ability to shed large numbers of potentially infective eggs into the environment and possibly water sources are the two key epidemiological reservoirs.

\subsection{Population and Individual Control Measures}

The European Scientific Council for Companion Animal Parasites (ESCCAP) recommends routine dehelminthisation of domestic pets to prevent dissemination of infective ova in the environment (ESCCAP, 2010). Lifelong control of worms, cleaning up of pet faeces, leash laws and faeces cleanup laws are also recommended. It is also recommended to fence playgrounds and sandpits to prevent entry of cats and dogs. Advised treatment protocols with anti-helminthics are as follows: Puppies should be treated from two weeks of age and every two weeks thereafter until two weeks after weaning; Kittens should be treated from three weeks of age and every two weeks thereafter until two weeks after weaning; Nursing bitches and queens should be treated concurrently with the first treatment of their offspring as they are known to develop patent infections at this time; Adults cats and dogs should be treated at least four times per year but ideally monthly treament would be best. If treatment is not performed, faecal examinations for the presence of helminths are recommended either monthly or every three months.

There is no recommended prophylactic treatment for humans. Despommier, (2003) remarked that more effective single-dose treatment regimens with safer drugs for pediatric patients could help limit the time of illness, provided that adequate medical infrastructure is already in place. However, Wisniewska-Ligier et al., (2012) described long term persistence of certain symptoms among children with toxocariasis, even after several rounds of treatment. ESCCAP (2010) guidelines also recommend minimising exposure of children to potentially infected environments and grooming dogs to minimise coat contamination by worm eggs. Education of staff, pet owners and the community is also highlighted with co-operation between medical and veterinary professions recommended to achieve this. In humans, hand washing and washing of fruit and vegetables is an important hygiene measure for minimisation of risk (Klapec and Borecka, 2012) and thorough cooking of meat is also advised (Nagakura et al., 1989).

Despommier, (2003) also stated that what is needed in terms of future control programs is the development of radical new approaches, such as effective molecular or DNA-based vaccines that offer the possibility of lifelong protection. The author hypothesised that oral baits laced with vaccine would be ideal for dealing with feral dog and cat populations, an approach similar to already existing protocols for the large-scale control of rabies in feral and wild animal populations. The ability to kill all Toxocara ova in contaminated soils is seen by most epidemiologists as a virtually impossible task, but if such a strategy could be found and safely implemented, extensive areas of previously contaminated land could be rendered Toxocarafree (Despommier, 2003). 


\subsubsection{Vaccines}

There is no available vaccine for Toxocara spp. and there is none currently under development. Barriga, (1988) suggested that complete resistance would require the prior control of the immunosuppression induced by the parasite as $T$. canis infections inhibit the production of homologous protective immunity and antibody responses to heterologous antigens. The author then stated that an antiT. canis vaccine to eliminate the parasite in dogs would be feasible. Furthermore, Hrčková, (2006) speculated that the strategy for Toxocara vaccine development could be focused on identification of natural antigens that are presented to the host's immune system during acute natural or experimental infection.

The gold standard treatment for human toxocariasis is currently benzimidazole administration, in conjunction with corticosteroids in the acute inflammatory phase of VLM and OT, but there have been no studies to investigate whether the two together are beneficial (Magnaval and Glickman, 2006). Surgical removal of granulomas is also a treatment option in certain cases of OT (De Souza and Nakashima, 1995).

\subsubsection{Hygiene measures}

Both the Center for Disease Control (CDC) in the United States and ESCCAP advise picking up and disposing of animal faeces (but not in recycleable waste or compost) (CDC, 2013; ESCCAP, 2010). Good personal hygiene, hand washing and washing of food are also advised. The CDC (2013) recommends washing hands with soap and water after playing with any animals, after any activites outdoors and before handling food. Education of children in the area of personal hygiene is also recommended as is not allowing them to play in areas soiled with animal faeces and teaching them that eating dirt or soil is dangerous. It is advised to clean the domestic pet's living area at least once per week, burying or disposing of pet faeces in waste disposal and washing hands after handling pet wastes (CDC, 2013).

\subsection{Environmental Occurrence and Persistence}

Definitive hosts such as dogs, cats and foxes release Toxocara spp. eggs in their faeces. Once released, eggs require a period of time under appropriate environmental conditions to develop to infectivity (Mizgajska-Wiktor and Uga, 2006). Once deposition has occurred, embryonation of Toxocara eggs is mainly influenced by both temperature and humidity (O'Lorcain, 1995; Stromberg, 1997; Gamboa, 2005). Variation in soil type has also been identified as a factor that influences the survival and infectivity of Toxocara eggs (Nunes et al., 1994). This section aims to highlight the existing data on environmental contamination with Toxocara ova and the significant gaps in our knowledge with respect to the presence of Toxocara ova in water.

\subsection{Detection Methods}

Quantification of environmental contamination with helminths poses major technical challenges: methods are needed that are both sensitive enough to estimate low-but epidemiologically relevant-concentrations of soiltransmitted helminths (STH), and cost-effective enough to be deployed in low resource settings where the impact of STH is highest (Collender et al., 2015). In order to quantify STH density in a sample, ova, larvae or their genetic material must be isolated from the environmental matrix and then concentrated. Recovery of STH from soils, biosolids, and water samples typically involves five key processes: homogenization, chemical dissociation from the matrix, filtration, sedimentation, and flotation (Collender et al., 2015).

Toxocara spp. recovery from soils varies between soil types (sand, silt clay or some combination of two or more), method (passive or centrifugal flotation), detergent (Tween 40, Tween 80, $\mathrm{NaOH}$ ) and flotation solutions (zinc sulphate, magnesium sulphate, sodium nitrate and sodium chloride) (Collender et al., 2015).

An assessment of several different flotation fluids found a saturated solution of magnesium sulphate plus $5 \%$ potassium iodide to be the most efficient in detecting ova in soil. Zinc sulphate was found to perform poorly by comparison (Quinn et. al.,1980).

Some Toxocara researchers pre-process samples by filtering them through coarse $4 \mathrm{~mm}^{2}$ sieves (O'Lorcain, 1994b; Quinn et al.,1980) or fine $150 \mu \mathrm{m}$ sieves (Zibaei et al., 2010; Fajutag and Paller, 2013; Horiuchi, Paller and Uga, 2013; Shrestha et al., 2007), prior to homogenization and other processing in order to remove twigs, rocks, and larger soil particles. One group found that by air-drying a $200 \mathrm{~g}$ soil sample overnight at room temperature, then sieving it down to $2 \mathrm{~g}$ of powdery sand using the $150 \mu \mathrm{m}$ sieve, up to a maximum of $40 \%$ efficient recovery may be achieved, meaning this method may provide greater throughput for soil samples at the expense of some sensitivity (Uga et al.,1997). A group in Kansas, USA reported that mechanical blending to disrupt large particles provides better results than sieving (Dada and Lindquist,1979). A recent study conducted in Germany (Kleine et al., 2016) evaluated a non-hazardous recovery method using Tween80 and sodium chloride and found that the evaluated method for egg recovery from soil showed above-average recovery rates.

The effectiveness of current methods to detect parasite eggs in wastewater and sewage sludge is 30 to $75 \%$ (Gaspard and Schwartzbrod, 1995). Zdybel et al., (2016) remarked that the composition of sludge makes it similar to soil with its high humus content making it difficult to investigate using traditional parasitological methods and that another feature of sewage sludge is the content of chemical substances applied during the hygienisation and dehydration processes. The 'own method' described by Zdybel et al., (2016) examined sludge dehydrated by polyelectrolytes, taking into consideration that polyelectrolytes used for dehydration of sewage 
significantly limit the effectiveness of parasitological examination of sewage sludges. The method described by Zdybel et al., (2016) was adapted to such types of substances. It was found to be several times more sensitive than other routinely used procedures and as a validated quantitative method it can be applied to official parasitological examination of sewage sludges providing reliable results (Zdybel et al., 2016).

In 2003, Gaspard and Schwartzbrod described a sampling strategy to accurately quantify the level of helminth contamination in sludge, accounting for both Nematodes (Ascaris, Trichuris, Capillaria and Toxocara spp.) and Cestodes (Hymenolepsis and Taenia spp.). They sampled from 2 wastewater plants in France using a modified zinc sulphate solution for flotation and concluded that the recommended sampling frequency can be limited to every 3 to 6 months.

The most current review of techniques for detecting and quantifying the total number of viable soil-transmitted helminth eggs in environmental samples was conducted by Amoah et al., (2017) and detailed conventional methods, nucleic acid based techniques, emerging techniques and future prospects with regard to environmental samples. Conventional techniques such as sedimentation, flotation and microscopy are traditionally used for soil, wastewater and sludge/biosolid analysis but can be laborious and time consuming. Nucleic acid based techniques allow for more sensitive, specific and rapid detection of pathogens. They can also enable species identification such as the duplex quantitative real-time PCR assay for the detection and discrimination of the eggs of T. canis and T. cati in soil and fecal samples (Durant et al., 2012). Emerging techniques include a parasite identification system using image analysis software to identify and enumerate parasite eggs (including $T$. canis) in wastewater with reported sensitivities of $80-100 \%$ and a specificity of $99 \%$ (Jimenez et al., 2016). A study carried out by Dabrowska et al., (2014) demonstrated that a LIVE/DEAD bacterial viability kit could be useful in the future for assessing the viabiility of Toxocara eggs occurring in sludge. The authors investigated the possibility of distinguishing between live and dead eggs in water by means of an assessment of the appropriate amount of dyeing mixture needed to distinguish between live and dead eggs. The investigation subsequently demonstrated that not only could different genera of Ascarids (Toxocara, Trichuris, and Ascaris) be identified but that their viability could also be ascertained.

Collender et al., (2015) concluded that methods for sampling and recovering STH require substantial advances to provide reliable measurements for STH control. The use of automated image identification and developments in molecular genetic assays offer considerable promise for improving quantification and viability assessment. Furthermore, subsequent validation and comparison of techniques is required in order to identify the most costeffective and efficient technique for uniform detection and quantification of STH eggs in environmental samples (Amoah et al., 2017).

\subsection{Data on Occurrence in the Environment}

Humans are known to become infected with Toxocara spp. following ingestion of embryonated eggs. Toxocara ova are not embryonated when passed in the faeces of dogs (Glickman, 1993) therefore, contamination is likely to come primarily from the environment (Morgan et al., 2013). Fisher (2003) also states the importance of cats as environmental contaminators with $T$. cati, although infection in cats and prevalence of $T$. cati in the environment has been studied in much lesser detail to date.

The literature on environmental contamination with Toxocara spp. ova is almost entirely confined to examination of soil (Pietrobelli et al., 2014). The presence of potentially infective or infective eggs of Toxocara spp. in the environment is one of the key routes of transmission to humans. Infected definitive hosts such as dogs, cats and foxes release their faeces, and the helminth eggs within them, into the environment. However, our understanding of the relative importance of the different host sources is incomplete (Morgan et al., 2013; Nijsse et al., 2015).

\subsubsection{In sewage and sludge}

Eggs of Toxocara could end up in sewage and primarily in sludge via disposal of cat and dog faeces to the sewer or via leaks in the system which allows run-off carrying soil and the eggs into the sewer. Sewage sludge (or biosolids) is the residue collected after treatment of the contents of urban drainage systems consisting of human waste, industrial effluents, discharges from animal or vegetable processing and run-off from land and roads (DEFRA, 2017). Sludge is rich in nitrogen, phosphorus and organic matter and is, therefore, a good source of nutritional requirements for crops, making it an attractive agricultural fertilizer. However, sludge may also contain pathogenic bacteria, viruses and parasites and improper management and use could pose a risk to human health as well as animal and plant health.

Zdybel et al., (2015) assessed 17 municipal mechanicalbiological wastewater treatment plants in Poland for the presence of parasite eggs at different stages of processing. Eggs of Toxocara spp. were detected in almost all stages of processing, including raw wastewater, preliminary sludge, excess sludge, fermented sludge and dehydrated sludge. Furthermore, the eggs detected were viable and were present with mean egg counts ranging from 2.67 eggs per 1 $\mathrm{g}$ dry matter in preliminary sludge to 0.25 eggs per $1 \mathrm{~g}$ dry matter in dehydrated sludge (final stage of processing).

In a study of a similar number of wastewater treatment plants in France, Schwartzbrod and Banas, (2003) investigated the level of parasite contamination of liquid sludge. Fresh sludge and discharged sludge (destined for agricultural use) were subjected to filtration, flotation and two rounds of phase separation before eggs were counted by microscopy. Out of a total of 194 samples analysed, 153 (79\%) were contaminated with helminth eggs, 135 of which contained viable nematode eggs and $77 \%$ were identified as Toxocara spp. 
In the 1980s, Reimers et al. (USEPA, 1981; 1986) conducted two large studies investigating the types and densities of parasites in sewage sludge in treatment plants in both the Southern (USEPA, 1981) and Northern (USEPA, 1986) United States. In the Southern study, sludge samples were collected from 27 municipal wastewater treatment plants over a year-long period, incorporating the four different seasons (spring, summer, autumn and winter). Toxocara spp. was among the four most common parasites found, with viable eggs being detected at least once from every plant sampled across all seasons.

\subsubsection{In Surface Water and Drinking Water}

The potential role of drinking water and the recreational use of water in transmission of Toxocara spp. may also be significant but has yet to be studied extensively (Beér et. al., 1999). Public beaches adjacent to municipal drinking water supplies just outside Moscow in Russia, were implicated as sources of Toxocara contamination (Beér et. al., 1999). The authors speculated that by allowing dogs and cats free access to these recreational areas, there is an increased likelihood that infective Toxocara spp. ova would enter the water of the lake. Bathers frequently and inadvertently drink water while wading and swimming, allowing for the possibility of ingesting infective eggs. Patients diagnosed with toxocariasis in the municipality confirmed bathing and involuntary swallowing of water in urban unflowing reservoirs.

\subsubsection{In Groundwater}

Pedley et al., (2006) have stated that, in general, the transmission of helminths in groundwater is unlikely, although not impossible, due to the size of the ova. There is no currently available data concerning Toxocara spp. in groundwaters.

\subsubsection{In Seawater and Shellfish}

There is no available data concerning Toxocara spp. in seawater and shellfish.

\subsection{Persistence}

Toxocara spp. eggs are extremely resistant to physical and chemical agents, and in temperate climates can survive well over winter, for 6 to 12 months (Fan et al., 2015a). Azam et al., (2012) investigated the influence of temperature on the development of $T$. canis larvae under laboratory conditions and found that in water at 15, 20,25, 30 and $35^{\circ} \mathrm{C}$ and at room temperature $\left(22^{\circ} \mathrm{C} \pm 1^{\circ} \mathrm{C}\right) \mathrm{T}$. canis eggs could develop to an embryonated stage at all tested temperatures with development occurring more quickly at higher temperatures. Survivability of eggs under moist, cool conditions may be up to 2 to 4 years or more (Azam et al., 2012). Several factors can influence the development, survival and availability of eggs to potential hosts, including light, temperature, $\mathrm{pH}$, humidity, the substrate and vegetation cover, and physical dispersal of eggs by definitive hosts or through the actions of birds, rainfall, flies, beetles, earthworms, and slugs (Fan et al., 2015a).

\subsection{Reductions by Sanitation Management}

Sanitation is the hygienic means of promoting health through prevention of human contact with the hazards of wastes, in particular via the treatment and proper disposal of human excrement, often mixed into wastewater. In the framework of agricultural wastewater reuse, the WHO has defined a parasitological quality for sewage with less than one nematode egg per litre (Gaspard and Schwartzbrod, 2003). Municipal facilities such as wastewater treatment plants must practice careful sanitation management to protect the health of communities.

\subsection{Wastewater Treatment}

Helminth ova size, density and shell all influence the egg's behaviour during processing and due to these properties it is very difficult to inactivate them so they are usually removed by sedimentation or filtration processes (Jimenez, 2007).

In 2007, Jimenez published data detailing the current known information concerning helminth ova removal during wastewater treatment. The author drew attention to the 1989 and 2006 WHO water reuse guidelines (WHO, 1989, 2006) where helminth ova are considered to be one of the main target pollutants to be removed from wastewater before reuse in agriculture and aquaculture. Wastewater treatment processes are described and reviewed as to which are useful in removing helminth ova from wastwater. Six types of processes are detailed: waste stabilisation ponds, reservoirs, constructed wetlands, coagulationflocculation, rapid filtration and the upflow anaerobic sludge blanket (UASB).

To remove helminth ova in waste stabilisation ponds where sedimentation is the most important factor, a minimum retention time of 5 to 20 days is required. Most ova are retained in the first anaerobic pond (Jimenez, 2007). In reservoirs and dams, helminth ova can be removed from wastewaters if retention times of $>20$ days are implemented (Jimenez, 2007). In order to remove 100\% of helminth ova in constructed wetlands, it would be necessary to coule the wetlands with a horizontal flow gravel bed, with most of the removal being achieved in a $25 \mathrm{~m}$ length (Rivera et al., 1995; Stott et al., 1999). Coagulation-flocculation processes such as chemical enhanced primary treatment (CEPT) and advanced primary treatment (APT) are both efficient at removing helminth ova while retaining organic matter, nitrogen and phosphorus in the water (Jimenez, 2007). Rapid filtration $(>2 \mathrm{~m} / \mathrm{h}$ ) removes 90 to $99 \%$ of helminth ova and this removal can be increased by 2 to $4 \log _{10}$ if coagulants are added (USEPA, 1992). The UASB ia an anaerobic biological reactor that can remove helminth ova through sedimentation and filtration in the sludge bed (Jimenez, 2007). The author emphasises the pressing need for more research in the field due to little information about helminth ova behaviour in wastewater. 


\subsubsection{Composting of faecal wastes}

Composting of waste is an aerobic process to aid decomposition of solid wastes. The process involves decomposition of organic waste into humus known as compost which can then be re-used, sometimes in an agricultural setting. As humans are a paratenic host for Toxocara spp., the life cycle of the parasite is arrested. The eggs do not pass through the gastrointestinal tract of humans and therefore composting of human fecal wastes would not be an appropriate action for reducing contamination of the environment with Toxocara spp. ova.

Composting during sludge treatment was investigated by Gantzer et al., (2001). The group monitored the bacterial and parasitological contamination to determine the impact of various sludge treatments on the two types of pathogens. Nematode eggs belonging to the following genera were identified: Ascaris (34.8\%), Trichuris (37.7\%), Toxocara $(13.7 \%)$ and Capillaria (13.8\%) (grouped together as 'nematode' eggs). Compost consisted of 1/3 sludge, 1/3 sawdust and aerated pile with a retention time of 21 days of ventilation and 7 days of suction at a temperature of 50 to $55^{\circ} \mathrm{C}$. The initial total concentration of nematode eggs in the compost was $6.2+/-6.7$ eggs per $10 \mathrm{~g}$ dry matter (DM) with $1.5+/-2.0$ eggs per $10 \mathrm{~g}$ DM being classed as viable. On exit, the total had decreased to $1+/-1.2$ total eggs/10 g $\mathrm{DM}$ and $<1$ viable eggs/10 g DM. Even though the initial count was low, it does seem that composting is a successful method in reducing viable egg load in sludge.

In contrast in 2007, Nemiroff and Patterson published a study analysing an experimental large-scale dog waste composting programme set up in 2004 in Quebec, Canada. The results were positive in that dog waste composting was found to be a feasible and highly functional method of managing large amounts of dog waste in an environmentally-friendly way but no testing for helminth eggs was performed so it is unknown whether this composting would reduce environmental contamination by Toxocara spp. eggs from definitive hosts such as dogs.

\subsubsection{Wastewater treatment facilities}

The relatively high number of eggs recovered from sludge is indicative of the high level of environmental contamination with Toxocara spp. ova. Once passed in the faeces of cats and dogs, Toxocara spp. eggs can remain viable in the soil for several years (Mizgajska-Wiktor and Uga, 2006) allowing for the possibility of the eggs being washed into public drains/sewers and therefore into wastewater treatment plants. If eggs survive wastewater treatment and retain viability, there is a possibility that infectious eggs could be applied to crops in sludge fertilizer and therefore pose a potential risk to human health.

Use of sludge fertiliser is under strict regulatory control specifically to monitor levels of potentially toxic elements that may build up on the soil.

Due to the potential pathogenic hazard, sludge applications on food crops are usually timed to coincide with planting, grazing or harvesting operations (DEFRA,
2017). Sludge must not be applied to growing fruit and vegetable crops, unless it is applied at least 10 months before harvest. The WHO recommends a limit of 3 to 8 helminth ova per gram of total solids for sludge which is destined for agricultural use (Jimenez, 2007). This is greater than the limit set by the United States Environmental Protection Agency of 1 helminth ova per gram of total solids (Jimenez, 2007).

In the previously discussed study conducted in France by Gantzer et al., (2001), which aimed to determine the impact of various sludge treatments on different species of bacteria and parasites, certain processes were found to perform better than others in terms of reducing viable nematode eggs in sludge. No different resistances (Ascaris, Trichuris, Toxocara and Capillaria) to the various treatment were observed and the authors therefore evaluated the global behaviour of all nematode eggs. Several treatment processes were analysed. These included - four biological treatments (mesophilic stabilisation, anaerobic mesophilic digestion, aerobic thermophilic digestion and composting), three chemical treatments (liming with slaked lime $(26 \%$ and $62 \%$ ) and quick lime; One heat treatment: drying at $108^{\circ} \mathrm{C}$; Two storage treatments from dehydrated sludge treated by anaerobic digestion and sludge treated with $62 \%$ slaked lime). The total concentration of nematode eggs in the sludge was not greatly affected by treatment or storage, and was in the range of $<1$ to 66 eggs $/ 10 \mathrm{~g} \mathrm{DM}$. However, the situation was different for mean viable egg counts which ranged from $<1$ to 30 eggs $/ 10 \mathrm{~g} \mathrm{DM}$. In France, sludge is considered to be sanitised when the threshold value for parasitic nematode eggs is $<3$ viable nematode eggs/10 g DM. In this study, it was found that four treatments - aerobic thermophilic digestion, composting, heat treatment and the storage of sludge treated with $62 \%$ lime - were successful and that no viable eggs were detected post treatment. Anaerobic mesophilic digestion, mesophilic stabilisation, treatment with slaked (26\%) or unslaked (25\%) lime, and the storage of dehydrated sludge did not produce sanitised sludge, demonstrating that the mesophilic processes studied were inefficient at eliminating viable nematode eggs. The longterm storage (240 days) of dehydrated sludge and the treatment of sludge with $62 \%$ slaked lime gave values at the limit of acceptability (3 eggs/10 g DM and 3.2 +/-0.8 eggs/10 g DM respectively). However, contrasting with these results, quicklime treatment (25\%) resulted in high levels of viable nematode eggs in the treated sludge $(10.5$ $+/-12.3$ eggs/10g DM). The authors speculated that the poor performance of treatment with quicklime, despite the $\mathrm{pH}$ reaching 12.4 , may be due to high initial concentrations of viable nematode eggs $(23.2+/-14.6$ eggs/10 g DM) and/or poor liming conditions.

A study in Poland by Zdybel et al., (2015) determined the degree of municipal wastewater contamination with intestinal parasite eggs of the genera Ascaris, Toxocara, and Trichuris at individual stages of treatment. The authors found that the largest number of viable eggs of Ascaris spp., Toxocara spp., and Trichuris spp. were found in sewage sludge collected from the primary settling tank. A slightly lower number of the eggs were found in the samples of excess sludge, which indicates that the 
sedimentation process in the primary settling tank is not sufficiently long to effectively separate parasite eggs from the treated sewage. The number of eggs of Ascaris spp. and Toxocara spp. in the fermented sludge was nearly 3 times lower than that in the raw sludge. The effectiveness of hygienisation of dehydrated sewage sludge by means of quicklime was confirmed in two wastewater treatment plants, with respect to Ascaris spp. eggs, in three plants with respect to Toxocara spp. eggs, and in one plant with respect to Trichuris spp. eggs. The mean reductions of numbers of eggs were $0.46 \log _{10}, 0.41 \log _{10}$, and $>2 \log _{10}$, respectively. In one wastewater treatment plant, a reduction in the number of viable eggs of Ascaris and Trichuris species was also noted as a result of composting sludge by $0.82 \log _{10}$ and $0.60 \log _{10}$, respectively.

The effects of mesothermic anaerobic or aerobic sludge digestion on the survivability and viability of eggs of a number of nematodes and cestodes including $T$. canis revealed that neither method of digestion evaluated destroyed the Toxocara eggs and the viability of the eggs was unaffected (Black et. al., 1982).

In the Reimers et al. studies (USEPA, 1981, 1986) parasite concentrations varied depending on whether the sample was collected pre-treatment (primary and secondary sludge) or post-treatment (aerobic or anaerobic digestion, filtration, lagoons or drying beds) with numbers of Toxocara spp. eggs per kg dry weight varying from 700 to 1,200 , respectively. It is noteworthy that egg viability in pre-treatment samples was $88 \%$ and only decreased to $52 \%$ in post-treatment samples (a decrease of $0.19 \log _{10}$ reduction). In the Northern United States study, sludge samples, from all stages of processing, were collected from 48 municipal wastewater treatment plants ranging in processing size from $<1$ million gallons per day to $>50$ million gallons per day (USEPA, 1986). In total, 20 different parasite species eggs or cysts were recorded and Toxocara spp. was among the four most commonly found, similar to results from the Southern United States study (USEPA, 1981). Parasite concentrations varied depending on the stage of processing the sludge sample was collected, with highest geometric means being detected in samples taken during digestion $(1,200)$ compared to undigested $(880)$ and post-digestion (330) samples. Egg viability decreased during processing from $78 \%$ in undigested samples to $74 \%$ during digestion and to $50 \%$ post-digestion (a decrease of $0.14 \log _{10}$ reduction overall).

In a small study of 3 municipal sewage treatment plants in Czechoslovakia, Horák, (1992) investigated the presence of parasites in five types of sludge sample - after anaerobic digestion at 25 to $26^{\circ} \mathrm{C}$, after aerobic digestion, after activation in ditches, after anaerobic digestion at 33 to $35^{\circ} \mathrm{C}$ and after anaerobic digestion at 38 to $42^{\circ} \mathrm{C}$. Sample sizes were small but Toxocara spp. was detected in all five types of sludge, with numbers ranging from 12 to 47 eggs per $100 \mathrm{~g}$ dried sludge, the highest being detected in samples collected after aerobic digestion. The author did not specify if the eggs were viable.

In a similarly small study in Chicago, Arther et al., (1981) investigated the presence of parasite ova in freshly digested sludge directly from anaerobic digesters and lagooned sludge from retention basins. Fifteen separate aliquots per sample were dried to determine the dry weight of sludge and then examined for parasite eggs. Toxocara spp. eggs were the second most abundant, following Ascaris spp., in lagoon sludge, with a mean of 173 eggs per $100 \mathrm{~g}$ dry sludge. Sixty four Toxocara spp. eggs in total were recovered from fresh anaerobically digested sludge and of these, 34 (53\%) were viable.

\subsubsection{Tertiary treatment}

This data has been included in the above section.

\subsection{Disinfection}

Disinfection is considered the primary mechanism for the inactivation/destruction of pathogenic organisms to prevent the spread of waterborne diseases to downstream users and the environment. It is important that wastewater be adequately treated prior to disinfection for any disinfectant to be effective (Wastewater Technology Fact Sheet Ozone Disinfection, EPA). Disinfection is accomplished both by filtering out harmful micro-organisms and also by adding disinfectant chemicals. Water is disinfected to kill any pathogens which may pass through filters and to provide a residual dose of disinfectant to kill or inactivate potentially harmful micro-organisms in storage and distribution systems. Possible pathogens include viruses, bacteria and parasites. Following the introduction of any chemical disinfecting agent, water is typically held in temporary storage - a contact tank or clear well to allow the process of disinfection to complete.

Aycicek et al., (2001) discovered iodine disinfectant solutions to be effective against embryonated eggs of $T$. canis. Iodine disinfectants produced a statistically significant difference in larvicidal ability when compared with a range of other other common disinfectants (glutaraldehyde, benzalkonium chloride, sodium hypochloride, potassium permanganate, ethyl alcohol, potassium hydroxide, phenol solutions). In the in vitro experiment, $T$. canis eggs were treated with disinfectant solutions at different time intervals, and larval motility was observed. Microscopic examinations revealed that T. canis eggs treated in 2.5 to $10 \%$ iodine solutions were completely non-motile at different times post-treatment respectively, whereas the eggs treated with the all other disinfectants were still motile after 24 hours. In the in vivo experiment, 1,000 embryonated eggs treated with disinfectants were inoculated into mice orally. Mouse brain tissue was then examined for larval presence on day 7 post-inoculation. No $T$. canis larvae were observed in mice inoculated with eggs treated with any of the iodine solutions but larvae were observed in the other study groups inoculated with eggs treated with the other disinfectants.

Treatment with 70\% ethanol inhibited embryogenesis of T. canis (Verocai et al., 2010). In contrast, sodium hypochlorite caused some morphological damage to ova but they were still able to develop into larva and remained infective for up to 2 weeks. Larvae derived from eggs treated with benzalconium chloride and formaldehyde- 
based disinfectant remained infective and were able to migrate when administered to mice. The authors also found that even long-term exposure to routinely used disinfectants had no effect on $T$. canis eggs. The disinfectants tested were products that are routinely used in veterinary hospitals, kennels, animal shelters and laboratories (benzalconium chloride, 70\% ethanol, 2 to $2.5 \%$ sodium hypochlorite solution, $7.99 \%$ formaldehydebased disinfectant). Tap water was used as a negative control.

Shalaby et al., 2011 carried out an experiment testing hydrogen peroxide plus dihroxy benzol at a $3 \%$ solution for use as a disinfection agent against $T$. canis eggs. The solution was found to have an ovicidal effect on unembryonated eggs after a 24 hour exposure with $99.73 \%$ (2.6 $\log _{10}$ ) inhibitory activity acheived. However, the solution was not found to have any effect on embryonated eggs, with no morphological changes apparent and no cessation of motility of larvae.

\subsubsection{Chlorine and ozone}

Ooi et al., (1997) found that despite treatment with ozone, unembryonated T. canis eggs were found to develop into viable second stage larvae. Viability of second stage larvae was also not affected by treatment with ozone as assessed by oral inoculation into mice and recovery of larvae from liver, lungs and digestive tract 48 hours postinfection. Jimenez-Cisneros, (2007) states that helminth ova cannot be inactivated with chlorine, UV light or ozone (in the latter case at least not with economical doses because $>36 \mathrm{mg}$ ozone per litre are needed with one hour contact time). Burge and Borgsteede, (1987) found that chlorine had no effect on Ascaris suum. Based upon this observation, it can be argued, due to their similar properties of resistance, that the same would be true for Toxocara spp.

\subsubsection{Irradiation and UV disinfection}

No data was found by the authors concerning irradiation or UV disinfection of Toxocara spp. However, Shamma and Al-Adawi, (2002) treated Ascaris lumbricoides ova in sewage sludge water with gamma-radiation of doses between 1.5 and $8 \mathrm{kGy}$. Major morphological changes were noted and eight weeks post treatment no larvae were detected within the shells. A later study investigated treatment of A. lumbricoides ova from filtered wastewater and secondary effluent with UV radiation (Al-Awadi et al., 2006) that accelerated the development of larvae with increasing UV dose. 


\section{References}

Al-Adawi, M.A., Albarodi, H., Hammoudeh, A., Shamma, M. and Sharabi, N. (2006). Accelerated larvae development of Ascaris lumbricoides eggs with ultraviolet radiation. Radiation Physics and Chemistry. 75, pp. 115-119. doi: 10.1016/j.radphyschem.2005.06.008.

Alderete, J.M.S., Jacob, C.M.A., Pastorino, A.C., Elefant, G.R., Castro, A.P.M., Fomin, A.B.F. et al. (2003). Prevalence of Toxocara infection in schoolchildren from the Butantã region, São Paulo, Brazil. Memorias do Instituto Oswaldo Cruz. 98, pp. 593-597. doi: 10.1590/s0074-02762003000500002.

Amoah, I.D., Singh, G., Stenström, T.A. and Reddy, P. (2017). Detection and quantification of soil-transmitted helminths in environmental samples: A review of current state-of-the-art and future perspectives. Acta Tropica. 169, pp. 187-201. doi: 10.1016/j.actatropica.2017.02.014.

Arther, R.G., Fitzgerald, P.R. and Fox, J.C. (1981). Parasite ova in anaerobically digested sludge. Journal (Water Pollution Control Federation). 53, pp. 1334-1338.

Aycicek, H., Yarsan, E., Sarimehmetoglu, H.O., Tanyuksel, M., Girginkardesler, N. and Ozyurt, M. (2001). Efficacy of some disinfectants on embryonated eggs of Toxocara canis. Turkish Journal of Medical Science. 31, pp. 35-39.

Azam, D., Ukpai, O.M., Said, A., Abd-Allah, G.A. and Morgan, E.Rene (2012). Temperature and the development and survival of infective Toxocara canis larvae. Parasitology Research. 110, pp. 649-656. doi: 10.1007/s00436-011-2536-8.

Barriga, O.O. (1988). A critical look at the importance, prevalence and control of toxocariasis and the possibilities of immunological control. Veterinary Parasitology. 29, pp. 195-234. doi: 10.1016/0304-4017(88)90126-4.

Bass, J.L., Mehta, K.A., Glickman, L.T. and Eppes, B.M. (1983). Clinically Inapparent Toxocara Infection in Children. New England Journal of Medicine. 308, pp. 723-724. doi: 10.1056/nejm198303243081216.

Bass, J.L., Mehta, K.A., Glickman, L.T., Blocker, R. and Eppes, B.M. (1987). Asymptomatic Toxocariasis in Children. Clinical Pediatrics. 26, pp. 441-446. doi: 10.1177/000992288702600902.

Beér, S., Novosil'tsev, G. and Mel'nikova, L. (1999). The role of the water factor in the dissemination of Toxocara eggs and the spread of toxocariasis in a megalopolis. Parazitologiia. 33(2), pp. 129-135.

Beautyman, W. and Woolf, A.L. (1951). An ascaris larva in the brain in association with acute anterior poliomyelitis. The Journal of Pathology and Bacteriology. 63, pp. 635-647. doi: 10.1002/path.1700630410.

Beaver, P.C., Snyder, C.H., Carrera, G.M., Dent, J.H. and Lafferty, J.W. (1952). Chronic eosinophilia due to visceral larva migrans; report of three cases. Pediatrics. 9, pp. 7-19.

Black, M.I., Scarpino, P.V., ODonnell, C.J., Meyer, K.B., Jones, J.V. and Kaneshiro, E.S. (1982). Survival Rates of Parasite Eggs in Sludge During Aerobic and Anaerobic-Digestion. Applied and Environmental Microbiology. 44(5), pp. 1138-1143.

Brunaska, M., Dubinsk, P. and Reiterov, K. (1995). Toxocara canis: Ultrastructural aspects of larval moulting in the maturing eggs. International Journal for Parasitology. 25, pp. 683-690. doi: 10.1016/0020-7519(94)00183-0.

Buijs, J., Borsboom, G., Renting, M., Hilgersom, W., van Wieringen, J., Jansen, G. et al. (1997). Relationship between allergic manifestations and Toxocara seropositivity: a cross-sectional study among elementary school children. European Respiratory Journal. 10(7), pp. 1467-1475.

Burge, W. and Borgsteede, F. (1987). Effects of various disinfectants on the development and survival possibilities of the pre-parasitic stages of Ostertagia ostertagi, Cooperia oncophora, and Ascaris suum. Tijdschr Diergeneeskd. 112, pp. 769-778.

Burke, T.M. and Roberson, E.L. (1985). Prenatal and lactational transmission of Toxocara canis and Ancylostoma caninum: Experimental infection of the bitch at midpregnancy and at parturition. International Journal for Parasitology. 15, pp. 
485-490. doi: 10.1016/0020-7519(85)90041-4.

Caldera, F., Burlone, M.E., Genchi, C., Pirisi, M. and Bartoli, E. (2013). Toxocara encephalitis presenting with autonomous nervous system involvement. Infection. 41, pp. 691-694. doi: 10.1007/s15010-012-0342-6.

CDC (2013). Toxocariasis - General Information. 2017, Centers for Disease Control and Prevention. Atlanta, Georgia.

CDC,. (2011). Ocular Toxocariasis -- United States, 2009-2010.

Coati, N., Schnieder, T. and Epe, C. (2004). Vertical transmission of Toxocara cati Schrank 1788 (Anisakidae) in the cat. Parasitology Research. 92, pp. 142-146. doi: 10.1007/s00436-003-1019-y.

Collender, P.A., Kirby, A.E., Addiss, D.G., Freeman, M.C. and Remais, J.V. (2015). Methods for quantification of soiltransmitted helminths in environmental media: current techniques and recent advances. Trends in parasitology. 31, pp. 625-639. doi: 10.1016/j.pt.2015.08.007.

Dabrowska, J., Zdybel, J., Karamon, J., Kochanowski, M., Stojecki, K., Cencek, T. et al. (2014). Assessment of viability of the nematode eggs (Ascaris, Toxocara, Trichuris) in sewage sludge with the use of LIVE/DEAD Bacterial Viability Kit. Annals of Agricultural and Environmental Medicine. 21, pp. 35-41.

Dada, B.J. and Lindquist, W.D. (1979). Studies on flotation techniques for the recovery of helminth eggs from soil and the prevalence of eggs of Toxocara spp in some Kansas public places. Journal of the American Veterinary Medical Association. 174, pp. 1208-1210.

Department for Environment Food \&amp; Rural Affairs (2017). Sewage sludge on farmland: code of practice. DEFRA. London.

De Souza, E.C. and Nakashima, Y. (1995). Diffuse unilateral subacute neuroretinitis. Report of transvitreal surgical removal of a subretinal nematode. Opthalmology. 102(8), pp. 1183-1186.

Despommier, D. (2003). Toxocariasis: Clinical Aspects, Epidemiology, Medical Ecology, and Molecular Aspects. Clinical Microbiology Reviews. 16, pp. 265-272. doi: 10.1128/cmr.16.2.265-272.2003.

Dinning, W.J., Gillespie, S.H., Cooling, R.J. and Maizels, R.M. (1988). Toxocariasis: A practical approach to management of ocular disease. Eye. 2, pp. 580-582. doi: 10.1038/eye.1988.108.

Dubey, J.P. (1978). Patent Toxocara canis Infection in Ascarid-Naive Dogs. The Journal of Parasitology. 64, pp. 1021. doi: $10.2307 / 3279714$.

Durant, J.-.F., Irenge, L.M., Fogt-Wyrwas, R., Dumont, C., Doucet, J.-.P., Mignon, B. et al. (2012). Duplex quantitative realtime PCR assay for the detection and discrimination of the eggs of Toxocara canis and Toxocara cati (Nematoda, Ascaridoidea) in soil and fecal samples. Parasites and Vectors. 5, pp. 288. doi: 10.1186/1756-3305-5-288.

Ehrhard, T. and Kernbaum, S. (1979). Toxocara canis et toxocarose humaine. Bulletin de l'Institut Pasteur. 77, pp. 225-287.

ESCCAP (2010). ESCCAP Guideline No. 1 Worm Control in Dogs and Cats, 2nd Edition. European Scientific Council for Companion Animal Parasites.

Fahrion, A.S., Staebler, S. and Deplazes, P. (2008). Patent Toxocara canis infections in previously exposed and in helminthfree dogs after infection with low numbers of embryonated eggs. Veterinary Parasitology. 152, pp. 108-115. doi: 10.1016/j.vetpar.2007.11.022.

Fajutag, A.J. and Paller, V.G. (2013). Toxocara egg soil contamination and its seroprevalence among public school children in Los Baños, Laguna, Philippines. Southeast Asian Journal of Tropical Medicine and Public Health. 44, pp. 551-560.

Fan, C.-.K., Holland, C.V., Loxton, K. and Barghouth, U. (2015). Cerebral Toxocariasis: Silent Progression to Neurodegenerative Disorders?. Clinical Microbiology Reviews. 28, pp. 663-686. doi: 10.1128/cmr.00106-14. 
Fan, C.K., Barghouth, U., Huang, Y., Chou, C., Chen, P., Liao, C. et al. (2015). Seroprevalence, disease awareness, and risk factors for Toxocara canis infection among primary schoolchildren in Makoko, an urban slum community in Nigeria. Acta Tropica. 146, pp. 135-140.

Fillaux, J. and Magnaval, J.-.F. (2013). Laboratory diagnosis of human toxocariasis. Veterinary Parasitology. 193, pp. 327-336. doi: 10.1016/j.vetpar.2012.12.028.

Finsterer, J. and Auer, H. (2007). Neurotoxocarosis. Revista do Instituto de Medicina Tropical de São Paulo. 49, pp. 279-287. doi: 10.1590/s0036-46652007000500002.

Fisher, M. (2003). Toxocara cati: An underestimated zoonotic agent. Trends in Parasitology. 19, pp. 167-170. doi: 10.1016/s1471-4922(03)00027-8.

Fu, C.-.J., Chuang, T.-.W., Lin, H.-.S., Wu, C.-.H., Liu, Y.-.C., Langinlur, M.K. et al. (2014). Seroepidemiology of Toxocara Canis infection among primary schoolchildren in the capital area of the Republic of the Marshall Islands. BMC Infectious Diseases. 14, doi: 10.1186/1471-2334-14-261.

Gamboa, M.I. (2005). Effects of temperature and humidity on the development of eggs of Toxocara canis under laboratory conditions. Journal of Helminthology. 79, pp. 327-331. doi: 10.1079/joh2005287.

Gantzer, C., Gaspard, P., Galvez, L., Huyard, A., Dumouthier, N. and Schwartzbrod, J. (2001). Monitoring of bacterial and parasitological contamination during various treatment of sludge. Water Research. 35, pp. 3763-3770. doi: 10.1016/s0043-1354(01)00105-1.

Gaspard, P. and Schwartzbrod, J. (1995). Helminth eggs in wastewater: quantification technique. Water Science and Technology. 31, pp. 443-446. doi: 10.1016/0273-1223(95)00309-b.

Gaspard, P.G. and Schwartzbrod, J. (2003). Parasite contamination (helminth eggs) in sludge treatment plants: Definition of a sampling strategy. International Journal of Hygiene and Environmental Health. 206, pp. 117-122. doi: 10.1078/1438-4639-00197.

Gavignet, B., Piarroux, R., Aubin, F., Millon, L. and Humbert, P. (2008). Cutaneous manifestations of human toxocariasis. Journal of the American Academy of Dermatology. 59, pp. 1031-1042. doi: 10.1016/j.jaad.2008.06.031.

Gibbons, L.M., Jacobs, D.E. and Sani, R.A. (2001). Toxocara malaysiensis N. Sp. (Nematoda: Ascaridoidea) from the Domestic Cat (Felis catus Linnaeus, 1758). J Parasitol.87, pp.660-665. doi: 10.1645/0022-3395(2001)087[0660:tmnsna]2.0.co;2.

Glickman, L. (1993). The epidemiology of human toxocariasis. Toxocara and Toxocariasis, Clinical, Epidemiological and Molecular Perspectives. (Lewis, J. and Maizels, R., ed.). Institute of Biology and the British Society for Parasitology. pp. 3-10.

Glickman, L.T., Magnaval, J.F., Domanski, L.M., Shofer, F.S., Lauria, S.S., Gottstien, B. et al. (1987). Visceral Larva Migrans in French Adults: A New Disease Syndrome?. American Journal of Epidemiology. 125, pp. 1019-1034. doi: 10.1093/oxfordjournals.aje.a114618.

Glickman, L.T. and Schantz, P.E.T.E.R.M. (1981). Epidemiology and Pathogenesis of Zoonotic Toxocariasis. Epidemiologic Reviews. 3, pp. 230-250. doi: 10.1093/oxfordjournals.epirev.a036235.

Good, B., Holland, C.V., Taylor, M.R., Larragy, J., Moriarty, P. and O'Regan, M. (2004). Ocular toxocariasis in schoolchildren. Clinical Infectious Diseases. 39, pp. 173-178.

Graeff-Teixeira, C., Morassutti, A.Loureiro and Kazacos, K.R. (2016). Update on Baylisascariasis, a Highly Pathogenic Zoonotic Infection. Clinical Microbiology Reviews. 29, pp. 375-399. doi: 10.1128/cmr.00044-15.

Holland, C.V. (2017). Knowledge gaps in the epidemiology of Toxocara: the enigma remains. Parasitology. 144, pp. 81-94. doi: $10.1017 / s 0031182015001407$. 
Holland, C.V. and Hamilton, C.M. (2013). The significance of cerebral toxocariasis: a model system for exploring the link between brain involvement, behaviour and the immune response. Journal of Experimental Biology. 216, pp. 78-83. doi: 10.1242/jeb.074120.

Holland, C.V. and Smith, H.V. (2006). Toxocara: The Enigmatic Parasite. CABI.

Horak, P. (1992). Helminth eggs in the sludge from three sewage treatment plants in Czechoslovakia. Folia Parasitologica (Praha). 39, pp. 153-157.

Horiuchi, S., Paller, V.G. and Uga, S. (2013). Soil contamination by parasite eggs in rural village in the Philippines. Tropical Biomedicine. 30, pp. 495-503.

Hotez, P.J. and Wilkins, P.P. (2009). Toxocariasis: America's Most Common Neglected Infection of Poverty and a Helminthiasis of Global Importance?. PLoS Neglected Tropical Diseases. 3, pp. e400. doi: 10.1371/journal.pntd.0000400.

Hrckova, G. (2006). Novel approaches to immunoprophylaxis for toxocariasis. Toxocara. The Enigmatic Parasite. (Holland, C.V. and Smith, H.V., ed.). CABI. pp. 174-194.

Jiménez, B. (2007). Helminth ova removal from wastewater for agriculture and aquaculture reuse. Water Science and Technology. 55, pp. 485. doi: 10.2166/wst.2007.046.

Jiménez, B., Maya, C., Velesquez, G., Torner, F., Arambula, F., Barrios, J.A. et al. (2016). Identification and quantification of pathogenic helminth eggs using a digital image system. Experimental Parasitology. 166, pp. 164-172. doi: 10.1016/j.exppara.2016.04.016.

JImenez-Cisneros, B.E. (2007). WATER AND HEALTH Vol. II - Helminth ova control in wastewater and sludge for agriculture reuse. Encyclopedia of Life Support Systems (EOLSS). pp. 5.

Keegan, J.Devoy and Holland, C.V. (2010). Contamination of the hair of owned dogs with the eggs of Toxocara spp. Veterinary Parasitology. 173, pp. 161-164. doi: 10.1016/j.vetpar.2010.06.010.

Klapec, T. and Borecka, A. (2012). Contamination of vegetables, fruits and soil with geohelmints eggs on organic farms in Poland. Annals of Agricultural and Environmental Medicine. 19, pp. 421-425.

Kleine, A., Janecek, E., Waindok, P. and Strube, C. (2016). Flotation and adherence characteristics of Toxocara canis and T. cati and a reliable method for recovering Toxocara eggs from soil. Veterinary Parasitology. 227, pp. 35-41. doi: 10.1016/j.vetpar.2016.07.023.

Kruchen, J., Blumke, J., Maaz, D., Demeler, J., Ramunke, S., Antolova, D. et al. (2017). Small rodents as paratenic or intermediate hosts of carnivore parasites in Berlin, Germany. PLoS One.

Le, T.Hoa, Anh, N.Thi Lan, Nguyen, K.Thi, Nguyen, N.Thi Bich, Thuy, D.Thi Thu and Gasser, R.B. (2016). Toxocara malaysiensis infection in domestic cats in Vietnam: An emerging zoonotic issue?. Infection, Genetics and Evolution. 37, pp. 94-98. doi: 10.1016/j.meegid.2015.11.009.

Liao, C., Sukati, H., D'Lamini, P., Chou, C., Liu, Y., Huang, Y. et al. (2010). Seroprevalence of Toxocara canis infection among children in Swaziland, southern Africa. Annals of Tropical Medicine and Parasitology. 104(1), pp. 73-80.

Li, M.-.W., Zhu, X.-.Q., Gasser, R.B., Lin, R.-.Q., Sani, R.A., Lun, Z.-.R. et al. (2006). The occurrence of Toxocara malaysiensis in cats in China, confirmed by sequence-based analyses of ribosomal DNA. Parasitology Research. 99, pp. 554-557. doi: 10.1007/s00436-006-0194-z.

Macpherson, C.N.L. (2013). The epidemiology and public health importance of toxocariasis: A zoonosis of global importance. International Journal for Parasitology. 43, pp. 999-1008. doi: 10.1016/j.ijpara.2013.07.004.

Magnaval, J. and Glickman, L. (2006). Management and treatment options for human toxocariasis. Toxocara: The Enigmatic Parasite. (Holland, C.V. and Smith, H.V., ed.). CABI. pp. 113-126. 
Magnaval, J.-.F., Galindo, V., Glickman, L.T. and Clanet, M. (1997). Human Toxocara infection of the central nervous system and neurological disorders: a case-control study. Parasitology. 115, pp. 537-543. doi: 10.1017/s0031182097001558.

Magnaval, J.-.F., Glickman, L.T., Dorchies, P. and Morassin, B. (2001). Highlights of human toxocariasis. The Korean Journal of Parasitology. 39, pp. 1-11. doi: 10.3347/kjp.2001.39.1.1.

Maizels, R.M. and Meghji, M. (1984). Repeated patent infection of adult dogs with Toxocara canis. Journal of Helminthology. 58, pp. 327. doi: 10.1017/s0022149x00025219.

Miyazaki, I. (1991). An Illustrated Book Of Helminthic Zoonoses. International Medical Foundation of Japan. pp. 494.

Mizgajska-Wiktor, H., Uga, S., Holland, C. and Smith, H. (2006). Exposure and Environmental Contamination. Toxocara. The Enigmatic Parasite. Wallingford. CABI. pp. 211,227.

Mizgajska-Wiktor, H. and Uga, S. (2006). Exposure and Environmental Contamination. Toxocara. The Enigmatic Parasite. (Holland, C.V. and Smith, H.V., ed.). CABI. pp. 211-227.

Morgan, E.R., Azam, D. and Pegler, K. (2013). Quantifying sources of environmental contamination with Toxocara spp. eggs. Veterinary Parasitology. 193, pp. 390-397. doi: 10.1016/j.vetpar.2012.12.034.

Nagakura, K., Tachibana, H., Kaneda, Y. and Kato, Y. (1989). Toxocariasis Possibly Caused by Ingesting Raw Chicken. Journal of Infectious Diseases. 160, pp. 735-736. doi: 10.1093/infdis/160.4.735.

Nathwani, D., Laing, R.B. and Currie, P.F. (1992). Covert toxocariasis-a cause of recurrent abdominal pain in childhood. The British journal of clinical practice. 46, pp. 271.

Nemiroff, L. and Patterson, J. (2007). Design, Testing and Implementation of a Large-Scale Urban Dog Waste Composting Program. Compost Science and Utilization. 15, pp. 237-242. doi: 10.1080/1065657x.2007.10702339.

Nichols, R.L. (1956). The etiology of visceral larva migrans: I. Diagnostic morphology of infective second-stage Toxocara larvae. The Journal of parasitology. 42, pp. 349-362.

Nijsse, R., Mughini-Gras, L., Wagenaar, J.A., Franssen, F. and Ploeger, H.W. (2015). Environmental contamination with Toxocara eggs: a quantitative approach to estimate the relative contributions of dogs, cats and foxes, and to assess the efficacy of advised interventions in dogs. Parasites and Vectors. 8, pp. 390-397. doi: 10.1186/s13071-015-1009-9.

Noh, Y., Hong, S.-.T., Yun, J.Young, Park, H.-.K., Oh, J.-.H., Kim, Y.Eun et al. (2012). Meningitis by Toxocara canis after Ingestion of Raw Ostrich Liver. Journal of Korean Medical Science. 27, pp. 1105. doi: 10.3346/jkms.2012.27.9.1105.

Nunes, C.M., Sinhorini, I.L. and Ogassawara, S. (1994). Influence of soil texture in the recovery of Toxocara canis eggs by a flotation method. Veterinary Parasitology. 53, pp. 269-274. doi: 10.1016/0304-4017(94)90190-2.

O'Lorcain, P. (1995). The identification of optimum conditions for the embryonation of Toxocara canis ova. International Journal of Environmental Health Research. 5, pp. 143-148.

O'Lorcain, P. (1994). Prevalence of Toxocara canis ova in public playgrounds in the Dublin area of Ireland. Journal of Helminthology. 68, pp. 237-241.

O'Lorcain, P. (1994). Epidemiology of Toxocara spp. in stray dogs and cats in Ireland. Journal of Helminthology. 68, pp. 331-336.

OOI, H.K., Lin, C.L. and Wang, J.S. (1997). Effect of ozone treatment on Toxocara canis eggs. Journal of Veterinary Medical Science. 60, pp. 169-173. doi: 10.1292/jvms.60.169.

World Health Organization, (WHO) (2006). Guidelines for the Safe Use of Wastewater, Excreta and Greywater, Volume 2. World Health Organization, (WHO).

overgaauw, P. and van Knapen, F. (2013). Veterinary and public health aspects of Toxocara spp. Veterinary Parasitology. 
193(4), pp. 398-403.

overgaauw, P., van Zutphen, L., Hoek, D., Yaya, F., Roelfsema, J., Pinelli, E. et al. (2009). Zoonotic parasites in fecal samples and fur from dogs and cats in The Netherlands. Veterinary Parasitology. 163(1-2), pp. 115-122.

Overgaauw, P.A.M. (1997). Aspects of Toxocara Epidemiology: Toxocarosis in Dogs and Cats. Critical Reviews in Microbiology. 23(3), pp. 233-251. doi: 10.3109/10408419709115138.

Pedley, S., Yates, M., Schijven, J.F., West, J., Howard, G. and Barrett, M. (2006). Pathogens: Health relevance, transport and attenuation. Protecting groundwater for health. (Schmoll, O., Howard, G. and Chilton, J., ed.). IWA Publishing. pp. 51.

Poulsen, C.S., Skov, S., Yoshida, A., Skallerup, P., Maruyama, H., Thamsborg, S.M. et al. (2015). Differential serodiagnostics ofToxocara canisandToxocara cati- is it possible?. Parasite Immunology. 37, pp. 204-207. doi: 10.1111/pim.12181.

Prociv, P. (1989). Toxocara pteropodis and visceral Larva migrans. Parasitology Today. 5, pp. 106-109. doi: 10.1016/0169-4758(89)90047-1.

Quinn, R., Smith, H.V., Bruce, R.G. and Girdwood, R.W.A. (1980). Studies on the incidence of Toxocara and Toxascaris spp. ova in the environment. 1. A comparison of flotation procedures for recovering Toxocara spp. ova from soil. Journal of Hygiene. 84, pp. 83-89. doi: 10.1017/s0022172400026553.

Reimers, R.S., Little, M.D., Englande, A.J., McDonell, D.B., Bowman, D.D. and Hughes, J.M. (1986). Investigation of Parasites in Sludges and Disinfection Techniques. US Environmental Protection Agency. Cincinatti, OH. pp. 234.

Rivera, I.G., Chowdhury, M.A.R., Huq, A., Jacobs, D., Martins, M.T. and Colwell, R.R. (1995). Enterobacterial repetitive intergenic consensus sequences and the PCR to generate fingerprints of genomic DNAs from Vibrio cholerae O1, O139, and non-O1 strains. Applied and Environmental Microbiology. 61, pp. 2898-2904.

Roddie, G., Stafford, P., Holland, C. and Wolfe, A. (2008). Contamination of dog hair with eggs of Toxocara canis. Veterinary Parasitology. 152, pp. 85-93. doi: 10.1016/j.vetpar.2007.12.008.

Rubinsky-Elefant, G., Hirata, C.E., Yamamoto, J.H. and Ferreira, M.U. (2010). Human toxocariasis: diagnosis, worldwide seroprevalences and clinical expression of the systemic and ocular forms. Annals of Tropical Medicine \&amp; Parasitology. 104, pp. 3-23. doi: 10.1179/136485910x12607012373957.

Schwartzbrod, J. and Banas, S. (2003). Parasite contamination of liquid sludge from urban wastewater treatment plants. Water Science and Technology. 47, pp. 155-163.

Segovia, J.M., Torres, J., Miquel, J., Llaneza, L. and Feliu, C. (2001). Helminths in the wolf, Canis lupus, from north-western Spain. Journal of Helminthology. 72, pp. 192-193. doi: 10.1079/JOH200152.

Shalaby, H.A., S Shafy, A.-., Ashry, H.M. and Moghazy, F.M.El- (2011). Efficacy of Hydrogen Peroxide and Dihydroxy Benzol Mixture (Disinfectant) on Toxocara canis Eggs. Research Journal of Parasitology. 6, pp. 144-150. doi: 10.3923/jp.2011.144.150.

Shamma, M. and Al-Adawi, M.A. (2002). The morphological changes of Ascaris lumbricoides ova in sewage sludge water treated by gamma irradiation. Radiation Physics and Chemistry. 65, pp. 277-279. doi: 10.1016/s0969-806x(02)00211-6.

Sharghi, N., Schantz, P.M., Caramico, L., Ballas, K., Teague, B.A. and Hotez, P.J. (2001). Environmental Exposure to Toxocara as a Possible Risk Factor for Asthma: A Clinic-Based Case-Control Study. Clinical Infectious Diseases. 32, pp. e111-e116. doi: 10.1086/319593.

Shrestha, A., Rai, S.K., Basnyat, S.R. and Rai, C.K. (2007). Soil transmitted helminthiasis in Kathmandu, Nepal. Nepal Medical College Journal. 9, pp. 166-169.

Smith, H., Holland, C., Taylor, M., Magnaval, J.-.F., Schantz, P. and Maizels, R. (2009). How common is human toxocariasis? Towards standardizing our knowledge. Trends in Parasitology. 25, pp. 182-188. doi: 
10.1016/j.pt.2009.01.006.

Smith, H. and Noordin, R. (2006). Diagnostic limitations and future trends in the serodiagnosis of human toxocariasis. Toxocara. The Enigmatic Parasite. (Holland, C. and Smith, H., ed.). CABI. pp. 89-112.

Sprent, J.F.A. (1958). Observations on the development of Toxocara canis (Werner, 1782) in the dog. Parasitology. 48, pp. 184-209. doi: 10.1017/s0031182000021168.

Stott, R., Jenkins, T., Bahgat, M. and Shalaby, I. (1999). Capacity of constructed wetlands to remove parasite eggs from wastewaters in Egypt. Water Science and Technology. 40, pp. 117-123. doi: 10.1016/s0273-1223(99)00454-0.

Stromberg, B.E. (1997). Environmental factors influencing transmission. Veterinary Parasitology. 72, pp. 247-264. doi: 10.1016/s0304-4017(97)00100-3.

Strube, C., Heuer, L. and Janecek, E. (2013). Toxocara spp. infections in paratenic hosts. Veterinary Parasitology. 193, pp. 375-389. doi: 10.1016/j.vetpar.2012.12.033.

Taylor, M., Keane, C., O'Connor, P., Girdwood, A.R. and Smith, H. (1987). Clinical features of covert toxocariasis. Scandinavian Journal of Infectious Diseases. 19(6), pp. 693-696.

Taylor, M.R.H. (2001). The epidemiology of ocular toxocariasis. Journal of Helminthology. 75, pp. 109-118.

Taylor, M.R.H. (2006). Ocular Toxocariasis. Toxocara. The Enigmatic Parasite. (Holland, C. and Smith, H., ed.). CABI. pp. 127-144.

Traversa, D., A di Regalbono, F., Di Cesare, A., La Torre, F., Drake, J. and Pietrobelli, M. (2014). Environmental contamination by canine geohelminths. Parasites \&amp; Vectors. 7(1), pp. 67.

Uga, S., Nagnaen, W. and Chongsuvivatwong, V. (1997). Contamination of soil with parasite eggs and oocysts in southern Thailand. Southeast Asian Journal of Tropical Medicine and Public Health. 28, pp. 14017.

USEPA (1992). Guidelines for Water Reuse. United States Environmental Protection Authority (1992). EPA/625/R-92/004.

USEPA (1981). Process Design Manual for Land Treatment of Municipal Wastewater EPA 625/1-81-013. USEPA.

Verocai, G., Tavares, P., F. Ribeiro, D.A., Correia, T. and Scott, F. (2010). Effects of Disinfectants on Toxocara canis Embryogenesis and Larval Establishment in Mice Tissues. Zoonoses and Public Health. 57(7-8), pp. e213-e216.

Walsh, M.G. (2011). Toxocara infection and diminished lung function in a nationally representative sample from the United States population. International Journal for Parasitology. 41, pp. 243-247. doi: 10.1016/j.ijpara.2010.09.006.

Wapenaar, W., Barkema, H.W. and O`Handley, R. (2013). Fecal Shedding of Toxocara canis and Other Parasites in Foxes and Coyotes on Prince Edward Island, Canada. Journal of Wildlife Diseases. 49, pp. 394-397. doi: 10.7589/2012-04-113.

Webster, G.A. (1958). A Report on Toxocara Canis (Werner, 1782). Canadian Journal of Comparative Medicine and Veterinary Science. 22, pp. 272-274.

WHO,. (1989). Health guidelines for the use of wastewater in agriculture and aquaculture. World Health Organization.

Wilder, H.C. (1950). Nematode endophthalmitis. Transactions of the American Academy of Ophthalmology and Otorlaryngology. 55, pp. 99-109.

Wisniewska-Ligier, M., Wozniakowska-Gesicka, T., Sobolewska-Dryjanska, J., Markiewicz-Jozwiak, A. and Wieczorek, M. (2012). Analysis of the course and treatment of toxocariasis in children a long-term observation. Parasitology Research. 110, pp. 2363-2371. doi: 10.1007/s00436-011-2772-y.

Wolfe, A. and Wright, I.P. (2003). Human toxocariasis and direct contact with dogs. Veterinary Record. 152, pp. 419-422. 
Won, K.Y., Kruszon-Moran, D., Schantz, P.E.T.E.R.M. and Jones, J.L. (2008). National Seroprevalence and Risk Factors for Zoonotic Toxocara spp. Infection. The American Journal of Tropical Medicine and Hygiene. 79, pp. 552-557. doi: https://doi.org/10.4269/ajtmh.2008.79.552.

Yoshikawa, M., Nishiofuku, M., Moriya, K., Ouji, Y., Ishizaka, S., Kasahara, K. et al. (2008). A familial case of visceral toxocariasis due to consumption of raw bovine liver. Parasitology International. 57(4), pp. 525-529.

Zdybel, J., Cencek, T., Karamon, J. and Klapec, T. (2015). Effectiveness of Selected Stages of Wastewater Treatment in Elimination of Eggs of Intestinal Parasites. Bulletin of the Veterinary Institute in Pulawy. 59, doi: 10.1515/bvip-2015-0008.

Zdybel, J., Karamon, J., Rozycki, M., Bilska-Zajac, E., Klapec, T. and Cencek, T. (2016). Characterisation of a new, highly effective method for detecting nematode eggs (Ascaris spp., Toxocara spp., Trichuris spp.) in sewage sludge containing flocculants. Experimental Parasitology. 170, pp. 198-206. doi: 10.1016/j.exppara.2016.09.011.

Zhu, X.Q., Jacobs, D.E., Chilton, N.B., Sani, R.A., B Y Cheng, N.A. and Gasser, R.B. (1998). Molecular characterization of a Toxocara variant from cats in Kuala Lumpur, Malaysia. Parasitology. 117, pp. 155-164. doi: 10.1017/s0031182098002856.

Zibaei, M., Abdollahpour, F., Birjandi, M. and Firoozeh, F. (2010). Soil contamination with Toxocara spp. eggs in the public parks from three areas of Khorram Abad, Iran. Nepal Medical College Journal. 12, pp. 63-65. 